\title{
THE EDUCATIONAL AFFORDANCES OF BLOGS FOR SELF-DIRECTED LEARNING
}

To be successful university learners, students need to develop skills in self-directed learning. This encompasses a range of cognitive and meta-cognitive skills including generating one's own learning goals, planning how to tackle a problem, evaluating whether learning goals have been met, and re-planning based on this evaluation. The educational affordances of blogs offer opportunities for students to become selfdirected learners in a supportive social environment. Based on qualitative analysis of design diaries written by 113 computer science students about a creative project, this paper presents a framework of the ways in which blogging activities can assist groups of students and their teachers in the development of a range of cognitive, social and self-directed learning skills. Although the students in this study used the commenting feature of blogs effectively for the purpose of praising and encouraging their peers, and giving hints and tips for solving problems, they did not coach each other on higher order skills. The paper discusses how this could be achieved in order to extend the educational value of blogging within a university learning community.

\section{Introduction}

There is increasing recognition of the importance of self-directed learning within higher education. As well as learning domain specific facts and concepts, students are expected to take responsibility for managing their own learning, requiring them to learn a range of transferable cognitive and meta-cognitive skills which will enable them to learn successfully in the future. The Quality Assurance Agency for Higher Education, the body responsible for checking that universities maintain academic standards in the UK, recently conducted a project in Scotland relating to "Enhancing the First Year Experience" (Mayes, 2009). The project recognised that the learning habits acquired by students in their first year were crucial with respect to their success as learners in future years of university and beyond. A key theme of the work was that of empowerment: "The question here is how to equip students, as close to the start of their studies as possible, with the skills, capacities and knowledge to be effective as independent learners for the rest of their programme, and for their subsequent employability, professional development, and, for that matter, lifelong learning"(Mayes 2009;4) The related concept of "learning how to learn" is predicted by the Beyond Current Horizons Project to be an important driver in education over the next thirty years: "It is, however, essential that learning to learn does become a key feature of the future of education, to ensure that at the heart of education is learning to be human and to take responsibility for one's place in a society which encourages and enables participation by all its citizens, to enable them to fulfil their own potential and shape the future for subsequent generations"(Higgins 2009;13). Higgins notes that "Learning how to learn" is a broad and sometimes nebulous concept which encompasses independence, meta-cognition, thinking skills, self regulation, self esteem and self efficacy.

Given the importance attached to the development of these skills, how can university educators help their students develop them, particularly in the crucial first year? Over the last decade, there has been interest among university educators about how online tools such as blogs can be co-opted to support learning. There appears to be a natural fit between current goals of higher education and the affordances of blogs in two main areas. Firstly, blogs can be seen as a convenient way to produce and share a reflective learning log and secondly, they can offer an audience for students writing within the safety of a learning community thus offering opportunities for collaborative learning. Deng and Yuen's framework of the educational affordances of blogs highlights the opportunities for the development of skills along cognitive and social/psychological dimensions (Deng \& Yuen, 2011). Affordances are defined as "the perceived and actual properties of the thing, primarily those fundamental properties that determine just how the thing could possibly be used" (Norman, 1998;9). In this case, the term "educational affordances" refers to the functional properties of 
blogging software which enable communities of users to read, write and comment on others' writing. Note that Deng and Yuen's use of the term is more abstract than Norman's who was specifically referring to the affordances of physical artefacts in the domain of product design. In the cognitive dimension, Deng and Yuen focussed on reflection, as defined by Dewey: "active, persistent and careful consideration of any belief or supposed form of knowledge in the light of the grounds that support it and the further conclusions to which it tends" (in Deng \& Yuen 2011; 443). Reflection is indeed an important aspect of self-directed learning, but selfdirected learning encompasses other high level skills which can also be developed through blogging. The purpose of this paper is to examine the ways in which the educational affordances of blogging can support wider self-directed learning. It does so by examining a different learning context for blogging: design diaries in engineering education rather than journals for responding to critical incidents in the domain of teacher education. Learning through design is a rich and complex task which "provides opportunities for students to incrementally construct, evaluate, discuss and revise both the models they are designing and their conceptions, thus encouraging students to engage in meta-cognitive activities such as planning and monitoring" (Puntambekar \& Kolodner 2005, 3). Design diaries can act as a catalyst for reflection and metacognition, making "thinking visible" and serving as a record of "students' journeys through the design process" (Puntambekar \& Kolodner 2005, 11).

Based on the qualitative analysis of design diaries in blog form written by 113 students on a computer science introductory programming module, the paper extends Deng and Yuen's framework by illustrating that these students used their blogs while planning their learning, generating learning goals, estimating task difficulty, monitoring progress, selecting between creative ideas, seeking help and evaluating both their own performance and the products they produced. As the students were writing about their experiences of working on an open ended creative project, it is anticipated that the extended framework will be relevant to educators in disciplines other than computer science which also require skills in conducting independent creative projects.

The paper first examines the definition of self-directed learning and defines its sub-skills, considering how affect is closely connected to the development of such skills. It then reviews the literature on on-line reflective writing in blog form including Deng and Yuen's framework of the educational affordances of blogs (Deng and Yuen, 2011). The results of a qualitative content analysis of blogs written by first year computer science students are outlined and synthesised into an extended framework which covers how the blogging activities of posting, reading and commenting can give opportunities for self-directed learning, social support and emotional expression. The paper concludes with directions for future research.

\section{Background}

\section{Self-directed learning}

There is a lack of clarity in the literature about the definitions of meta-cognition, self-regulation and selfdirected learning (Alexander, 2008; Kaplan, 2008; Loyens, Magda, \& Rikers, 2008). Self-directed learning is a process in which the learner takes the initiative and responsibility for setting his own learning goals, identifying and addressing gaps in his learning, identifying resources, selecting and carrying out learning strategies and evaluating his own learning (Loyens, Magda, \& Rikers, 2008) The learner may receive varying degrees of teacher or peer support for these tasks. (Loyens, Magda, \& Rikers, 2008) compare self-directed learning with self regulated learning in the context of problem based learning, identifying that self-directed learning is a broader concept which includes self regulated learning. In a self-directed learning environment, students have more freedom to generate and pursue their own goals, and undertake critical evaluation of the materials they select. The self-directed learner initiates the learning task, whereas in self regulated learning, the task could be set by the teacher. 
In self regulated learning environments, learners have control over directing their cognitive and metacognitive resources to achieve a learning goal. Actively engaging in the process of their learning, they set themselves sub goals, plan their activities, evaluate the success of those activities and replan their work based on this. According to (Zimmerman \& Tsikalas, 2005), self-regulation is an iterative three phase process of forethought, performance and self-reflection. In the forethought phase, the learner prepares for learning using metacognitive skills such as task analysis, planning and setting goals. Sources of self-motivation such as confidence about one's own ability and intrinsic motivation are also important in this stage to give the learner impetus. During the performance phase, the learner employs various metacognitive strategies to carry out a learning task, while using meta-cognitive skills to monitor and improve performance. In the self-reflection phase, the learner looks back and evaluates her performance on the previous phases. This involves not only metacognitive skills but also motivational and emotional reactions to the task. These can in turn influence the learner's attitudes and beliefs in her own ability for the next iteration of the cycle.

Self regulated learning involves meta-cognition, intrinsic motivation and other motivational factors, such as willingness to make an effort and persistence (Vrugt \& Oort, 2008). Learners' attitudes to learning, their motivations and emotions mediate their self-regulation in complex ways.

\section{Motivation and motivational regulation}

(Wolters, 2003)regards motivational regulation as an important aspect of self-regulation. He distinguishes between motivation and motivational regulation as follows: "motivation refers to a student's willingness to engage in and persist at a task" (190) while motivational regulation "can be described as the activities through which individuals purposefully act to initiate, maintain or supplement their willingness to start or provide work toward, or to complete a particular activity or goal (i.e. their level of motivation). This form of regulation is achieved by deliberately intervening in, managing or controlling one of the underlying processes that determine this willingness" (190). He reviews strategies which learners may use to regulate their motivation including setting consequences for one's own behaviour such as rewards or punishments; engaging in goal directed self talk to persuade oneself of the benefits of working; enhancing interest by altering a tedious task to make it more enjoyable or challenging; restructuring the environment to reduce the possibility of distraction; managing self-efficacy; and regulating one's emotional response to a learning situation.

(Elliott \& C S Dweck, 1988) consider how learners' goals relate to motivation and achievement. Those with performance goals use learning situations to try to validate their ability through obtaining positive judgements and avoiding negative judgements. This is associated with a fixed mindset (Dweck 2007)in which an individual believes his abilities are not malleable or subject to improvement. In contrast, individuals with mastery goals attempt to develop their abilities overtime and respond to failure as a source of feedback as to how they can improve their performance. This approach to learning is associated with a growth mindset (Dweck 2007)-the attitude that one's basic abilities can be developed through effort and perseverance. (Vrugt \& Oort, 2008) developed a model of effective self regulated learning derived from path analysis of exam scores and self report questionnaire data of first year learners. They found a positive relationship between intellectual ability and self-regulation learning, and confirmed that more active engagement in learning and self regulation resulted in higher exam scores. Students who took a mastery approach to learning (i.e. those who believed that effort leads to an improvement in performance) were better able to deal with resource management, and were more inclined to employ meta-cognition. In contrast, less effective self regulators tended to focus on performance goals such as avoiding negative performance (e.g. trying to avoid appearing stupid) which was not linked to the use of meta-cognition, or deep cognitive processes. There is some evidence from this study that a combination of mastery and performance approach goals can be effective; intrinsically motivated students can also benefit from the extrinsic motivation of avoiding being judged negatively for poor work. 
(Coutinho and Neuman 2008) found that self efficacy - a person's perception of their own ability to achieve success- was a strong predictor of performance among undergraduate psychology students, whereas metacognition was a weaker predictor. The use of mastery and performance goals were predictors of self efficacy; the students who focussed on developing their competencies and seeking knowledge and understanding of an area, and those who aimed to demonstrate competency to others tended to believe in their ability to succeed more than those who tried to avoid mastery, or focussed on avoiding showing a negative performance to others. Based on these findings, Coutinho and Neuman recommend that teachers should aim to foster self efficacy and observe that "the richest learning environment could be one that fosters support and encouragement and helps to build faith in abilities and skills" (Coutinho and Neuman, 2008;147).

(Wolters, 2003)notes that it is possible for students to "monitor, evaluate and purposefully control their own expectations, perceptions of competence or self-efficacy for tasks" (p198) and that this is a significant form of motivational regulation. He notes that strategies for efficacy management include the self setting of subgoals in the service of meeting a challenging goal; efficacy self-talk in which a student gives herself a pep talk along the lines of "you can do it if you keep working"; and defensive pessimism in which the student highlights her own lack of ability or unpreparedness to make her anxious enough to begin studying.

\section{Metacognition}

(Flavell, 1979) believed that meta-cognition consisted of interactions between meta-cognitive knowledge, meta-cognitive experiences, goals and strategies. He considered meta-cognitive knowledge to be world knowledge about the cognition of oneself and other people, and the nature of tasks. Meta-cognitive experience refers to cognitive and affective experiences arising from and relating to intellectual tasks. These can arise at any stage of a task, and can be of varying length from a fleeting sense of puzzlement to an ongoing feeling that one is likely to fail. Flavell believed that such experiences were likely to arise during tasks which stimulate "careful, affect highly conscious thinking" (Flavell 1979; 908)because "such situations provide many opportunities for thoughts and feelings about your own thinking to arise, and in many cases, call for the kind of quality control that meta-cognitive experiences can help supply" (Flavell 1979; 908). He also acknowledged that meta-cognitive knowledge and experiences have some overlap. Meta-cognitive goals are the "objectives of cognitive enterprise" and meta-cognitive strategies are used to regulate the progress of cognitive tasks. Examples of meta-cognitive activities include planning, predicting, guessing, and monitoring (Noushad, 2008). An aspect of meta-cognitive monitoring is self appraisal: an activity which requires critical evaluation of one's own performance in order to take steps to correct it. Noushad notes that learners require a supportive affective environment in order to feel comfortable with the challenging task of self appraisal.

\section{Affect and academic emotions}

A highly related concept to self-directed learning is affect. Boekaerts, in considering the relationship between motivation, affect and learning, states that "emotions experienced during goal pursuit are sources of information that students interpret and use" (Boekaerts 2003;186). This is consistent with Flavell's position on meta-cognitive experience, particularly because of Boekaert and colleagues' empirical evidence that students' evaluation of their own performance is influenced by their emotional state. Students experiencing a higher intensity of positive emotion were likely to assess their performance more favourably and vice versa. Similarly, students who believed they had the resources to complete a task, had confidence in their own ability to complete the task and those who enjoyed the task were more likely to evaluate their performance as successful afterwards. They also observed that students tended to experience negative emotions when they realised that there were obstacles in the way of achieving their goal, or if they realised their progress was slow. This illustrates that the meta-cognitive behaviours of goal setting and monitoring are mediated by the learner's emotional state; affect and meta-cognition are intertwined. This was apparent from the analysis of the blog corpus described in later in the paper. 
In a review of research on how academic emotions relate to self-regulated learning and achievement, (Pekrun, Goetz, Titz, \& Perry, 2002) found that student's emotions are significantly related to self-regulation as well as motivation, learning strategies, cognitive resources, and academic achievement. They provide a taxonomy of eight "academic emotions" which they define as "emotions which are directly related to academic learning, classroom instruction or achievement" p5. These are the positive activating emotions of enjoyment, hope, and pride; the positive deactivating emotion of relief; the negative activating emotions of anger, anxiety, shame; and the negative deactivating emotions of hopelessness and boredom. The most prevalent emotion encountered by students in their study was anxiety, but despite this, overall positive and negative emotions were equally prevalent. Positive activating emotions were found to enhance academic motivation and achievement, whereas negative deactivating emotions can diminish both. Positive emotions were positively linked to the use of metacognitive strategies, elaboration, organisation and critical thinking. Further, findings suggest that positive emotions foster self-regulated learning whereas negative emotions encourage students to rely on external guidance. This may also work in reverse: self-regulation may be a positive emotional experience whereas being directed by others may cause anger, anxiety or boredom. However, Pekrun and colleagues note that much more research is required in this area, as so far a disproportionate amount of work has focussed only on anxiety.

As noted above, Wolters identifies emotional regulation - the ability to "monitor, evaluate and change the occurrence, intensity and duration of the particular emotional experience" - as an aspect of motivational regulation. Emotional regulation is important because learners who feel emotionally challenged by a learning environment will focus on coping with their emotions rather than on problem solving (Järvenoja \& Järvelä, 2009).

\section{Self-directed learning and other learners}

From a social cognitive perspective, the development of self-directed learning by its nature requires social interaction with more able partners (Zimmerman \& Tsikalas, 2005). Students develop self regulatory skills initially through social training, but gradually acquire the necessary skills for themselves. (Zimmerman \& Tsikalas, 2005) summarise the four stages of this process: the observation level where the student can recognise a good performance when presented by a proficient other; emulation level where the student can duplicate the performance and strategies of a proficient other on a similar task; self controlled level where the student practices on her own without an explicit model, although perhaps by imagining the strategies an expert peer or teacher might use to complete the task. The fourth level is self-regulated, by which time the student is sufficiently practiced at the task so that they can perform it in dynamic and personal contexts and adapt their strategies based on performance outcomes.

For collaborative learning, the context in which blogs are often used, the concepts of co-regulation and shared regulation are also relevant. In the former, the learners aim to assist in regulating each other's individual behaviour in pursuit of individuals' goals, while in the latter, the members of a group join together to consensually regulate group processes to fulfil a goal shared by the whole group (Järvenoja \& Järvelä, 2009). Collaborative learning also raises additional motivational challenges and evokes emotions for learners, due to conflicts arising from individual differences, cognitive conflicts and communication difficulties between group members (Järvenoja \& Järvelä, 2009). (Sanna Järvelä, 2007) argue that emotional regulation from both a group and individual perspective is therefore a crucial part of collaborative learning.

Another social component of self-directed learning is diagnosing when it is necessary to seek help with a problem, identifying what sort of help to ask for (Harris, Bonnett, Rosemary Luckin, \& Yuill, 2009) and finding an appropriate source of assistance, whether from an instructor, a peer or another resource. (du Boulay et al., 2010)provide a conceptual framework for intelligent tutoring systems which could be designed to support students in the regulation of cognition, affect and motivation. In the context of blogs, which do not generally 
provide automated support, the student's help-seeking behaviour from peers will be mediated through the software but the software itself does not provide intelligent assistance. Computer mediated peer support via blogging is discussed in the next section.

\section{Blogging as an educational tool}

Blogging can be a medium for reflective writing which in turn can promote learning (Boud, 2001). Reflection is the process of exploring an experience in order to learn something new from it. This is an important aspect of self-directed learning. In Zimmerman and Tsikalas' view, self-reflection is a phase in the cyclical model of selfregulation where the learner makes judgements about her performance during a learning task (Zimmerman \& Tsikalas, 2005). There is an important emotional component involved; Boud writes "Reflection involves taking the unprocessed, raw material of experience and engaging with it as a way to make sense of what has occurred. It involves exploring often messy and confused events and focusing on the thoughts and emotions that accompany them." (Boud 2001; 10). A written journal can be a place both for both recording learning experiences and processing them in order to understand their implications. Occasions which can be appropriate for reflective journal writing include writing in anticipation of events, reflection in the midst of events, and reflecting after undergoing a new experience. Boud also points out some barriers to reflective writing in a learning situation. There is the issue of privacy: to what extent can students feel comfortable writing about the emotional component of their feelings honestly when they know it will be read by their peers and staff? This is compounded by the fact that learning journals are often assessed. Students, particularly those with a performance approach, may be reluctant to write about misconceptions or difficulties they have with the course material in case this results in a negative assessment of their abilities. It is therefore important to clearly explain to students who their audience will be, and how the journal will be marked.

With the increase in popularity of blogging software in the early 2000s, educators began to see the potential of it for learning situations including reflective writing. In 2004, Williams and Jacobs concluded that "blogs have the potential, at least, to be a truly transformational technology in that they provide students with a high level of autonomy while simultaneously providing opportunity for greater interaction with peers"(Williams \& Jacobs 2004; 145). In a survey of 104 MBA students' attitudes to blogging, they found that $77 \%$ of students believed that writing and commenting on blogs enhanced student interactivity and increased "the level of meaningful intellectual exchange between students"(145). The authors recommended that it is important to give students direction about how to blog and what benefits they might expect to experience from it. (Ferdig \& Trammell, 2004) commented on the potential benefits of blogging in an educational setting, remarking that they are ideal spaces for students to make meaning and publish their reflections, thoughts and understandings for an authentic audience. They identified the comments feature as useful for promoting peer feedback and scaffolding of new ideas. Additionally, in their view, blogging can increase student ownership and interest, give opportunities for students to legitimately interact within a community of practice and celebrate diverse points of views.

However in spite of this potential, more recently (Kerawalla, S Minocha, Kirkup, \& Conole, 2009) warn that it can be difficult for educators to implement blogging as a successful learning activity, citing a range of previous studies which reported lack of engagement in blogging by students. In response to this, the authors developed a framework for educators and learner bloggers based on interviews with Masters level students from an e-learning course who had written reflective blogs on a voluntary basis during their course. The students used the blogs for a variety of purposes including carrying out course related activities to share with other students, carrying out course activities but for their own benefit rather than for sharing, keeping a learning journal and keeping a personal online document store. In their framework the authors propose a set 
of questions designed to encourage students to think about how to begin and subsequently sustain a blog. The questions are posed at a high level, referring to the audience, community, and presentation of the blog as well as technological considerations.

Luehmann discusses the use of blogging as a means of reflection in adult learners by examining a detailed case study of a science teacher who blogged her experiences of teaching in an inner city school (Luehmann, 2008). Luehmann argues that the teacher used the blog as a tool to develop her professional identify, and to think critically at a distance about her classroom practice and more general issues relating to education in her local context. The teacher found the blog useful as a method for recording, easily retrieving and revisiting her own thoughts and experiences over time. The author concludes that the blog format offered the teacher an opportunity for self-directed learning and meta-cognition by enabling her to write about issues which were important to her at the moment they cropped up, thus providing the benefits of a personal learning journal combined with the motivational power of a real audience. The researcher concludes "This study also provides empirical support for some of the claims made in the blogging literature about the unique learning affordances blogging can offer learners in general and teachers more specifically. These include the opportunity to be self-directed, to reflect and engage in meta-cognition, to further develop one's thinking because of interaction with an audience, to play the role of knowledge-broker, and to engage in identity work." (335).

From the perspective of the benefits of blogging on collaborative learning, Minocha provides a literature review of educational uses of social software, including blogs. "Social software seems to match well with modern thinking about educational practice. In particular, it promises learners new opportunities to be independent in their study and research. Social software tools encourage a wider range of expressive capability. They facilitate more collaborative ways of working and they furnish a setting for learner achievements to attract an authentic audience"(Minocha 2009;356). She identifies how social software is consistent with educational theories such as collaborative constructivism, and documents that common applications of blogs in higher education include active learning, reflective practice and learning journals.

In a companion publication, the author reports on empirical data on the use of social software in higher and further education, based on 26 case studies from UK institutions (Minocha 2009a). The findings enumerated benefits to educators including being able to track students' progress and give feedback early, and being able to teach more interactively. They also identified challenges to the educator of social software tools, such as the lack of guidelines for designing effective learning activities using such software or the workload involved in providing feedback on high volumes of student writing, particularly for student blogs. Benefits for students included the development of collaborative skills, for example when constructing group reflective blogs and giving and receiving peer feedback through blog comments. Challenges for students included worries about their work being in the public domain (although student work can be protected in a university VLE), the learning curve of getting to grips with new technology and deriving educational value from using the tools in situations where their co-learners did not contribute, for example by commenting on blog posts.

(Deng \& Yuen, 2011)propose a framework for the educational affordances of blogs which is structured around the activities of writing, reading and commenting on blogs. Students can learn from these activities in the social/psychological dimension and the cognitive dimension. In the social/psychological dimension, writing a blog entry gives an opportunity for self expression, reading a blog enables social connection and commenting facilitates social interaction. In the cognitive dimension, self-reflection is supported by blog writing, reflection is triggered by blog reading and reflective dialogue by commenting on a blog. 


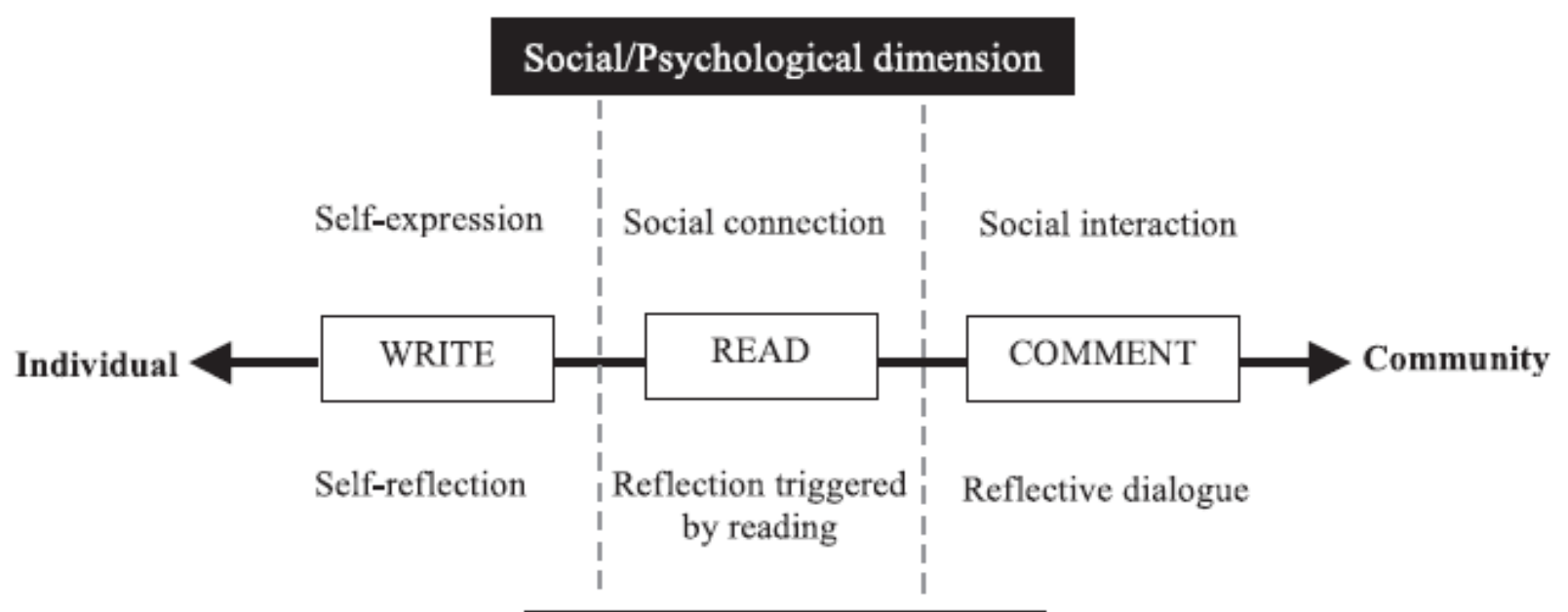

Cognitive dimension

Fig. 5. The new framework for the educational affordances of blogs.

Figure 1. Deng and Yuen's framework.(Deng \& Yuen, 2011)

Deng and Yuen's work is based on interviews and content analysis of blogs from two classes of Bachelor of Education students (37 students in total) in Hong Kong. The authors perceptively note that "a distinct characteristic of academic blogs is the fusion of personal narratives and critical reflection. Academic blogs bring a reflective cognitive dimension to personal narrative and introduce an emotional and social dimension to formal academic work that often accentuates cognitive or intellectual tasks" (450). But what sort of cognition - or indeed meta-cognition -is demonstrated in educational blogs? In Deng and Yuen's study, only around one third of the blog posts from one class and one half of the posts from the other class contained reflective thinking according to the criteria they used for content analysis which included justifying or giving reasons for one's own actions; relating teaching practices to teacher competencies; considering personal, professional or social problems relating to teaching; and discussing moral or ethical issues. These aspects of reflection are of particular relevance to trainee teachers, but they do not represent the full spectrum of learning which could be supported by blogging activities, such as the meta-cognitive potential identified by (Luehmann, 2008).

The contribution of this paper is to further develop the educational blog affordances framework by examining the dimension of self-directed learning in the context of using blogs as a form of design diary for a creative design project. The extended framework illustrates how the affordances of blogs can support the development of skills in planning learning, generating goals, estimating task difficulty, monitoring progress, selecting between creative ideas, seeking help and evaluating both one's own performance and product. The framework was revised based on content analysis of 113 blog written by first year computer science students in a Scottish university, but it is anticipated that the findings generalise beyond the domain of computer science to other disciplines which require complex open ended creative design tasks.

\section{Methods}

\section{Participants and context}

The introductory module in Interactive Systems was developed as part of newly restructured degree programmes in Computer Science and Information Systems at a small engineering focussed university in 
Scotland. The objectives of the module were to give students a motivating introduction to programming and multimedia systems development lifecycles and to help them to develop study skills which would be useful throughout their university careers. This compulsory module ran in the first semester of first year, for 12 weeks. Students attended one lecture and one two hour lab per week. The module was assessed by $100 \%$ coursework in the form of a portfolio comprised of a design diary (25\%), peer reviews (25\%) and an interactive pet created in the Second Life programming environment (50\%). The interactive pet marks were allocated for both the visual appearance of the pet which required 3D object building skills, and its interactive behaviour which required programming skills. There were several elements in the pedagogical design of the module. One of the most important aspects was that the students should work independently on a creative design project within a supportive environment. It was intended that the students should develop skills in directing their own projects, from choosing a suitable project (in this case deciding which pet to make) to evaluating the success of their enterprise. Another important aspect was to encourage the students to work effectively with their peers. There were various opportunities for peer learning: working in problem solving pairs in lectures, pair programming in labs, formal peer review of pets in week 10, and informal support in the form of peer blog comments throughout the semester. A third design element for the module was that it should be a positive affective experience for the students. As learning programming can be a frustrating and demoralising task, we aimed to counterbalance this by providing a fun, supportive and encouraging atmosphere in which students could build confidence and take pride in their work. Support of self-directed learning skills was intended to be distributed across face to face interactions with teaching staff in labs and lectures; static prompts in written lab exercises; blog comments from teaching staff and peer interactions as described previously.

\section{Design diaries}

The focus for this paper is on analysis of the students' self-directed learning skills as demonstrated in their design diaries. The instructions for completing the design diaries (also referred to as learning logs) in the assignment specification are shown in Figure 2. At the second lecture the instructors explained in detail what was required in a learning log, what sorts of things the students should write about, gave some examples of good reflective writing and demonstrated how to use the blogging software in the Blackboard virtual learning environment which is used throughout the university. Students were divided into study groups of five and asked to comment regularly on their group members' blogs. Students could also read and comment on the blogs of any other classmates, but the blogs were not available to users outside the class.

\footnotetext{
"Throughout the project you will keep a learning log of what you have learned. A learning log is a diary of what you learned throughout the module. This will help us to assess the rest of your work - it is your chance to demonstrate the learning process you went through to arrive at your portfolio. This means that even if you encounter lots of problems and don't achieve what you were aiming for, you can still get credit for trying. The learning log should include a record of your ideas and how they changed as you learned more, and a log of the problems you encountered and how you fixed them. The last entry should reflect on how successful you think your portfolio is and why. You are expected to update the blog regularly throughout the term.

You will keep your learning log using the blog facility in Blackboard. You are expected to read blogs written by the other members of your group, and give them helpful comments. In return, their comments will help you. We will also read your blog from time to time to give you feedback."
} 
The students were explicitly prompted to write blog entries at the end of weekly lab worksheets. Lab sheets in the early stages of the module contained prompts such as "Reflection. 15 minutes before the end of the session, stop working in Second Life and think about what you have done in this lab. Write in your blog about:

a. What you have learned today

b. What problems did you come across and how did you solve them?

c. What do you want to work on next time?"

As the module progressed, the lab worksheets contained less specific prompts of what sort of questions to consider, giving only more general reminders such as "Remember to write about what you have learned in your blog, and to comment on your group members' learning logs".

\section{Qualitative analysis methodology}

Blogs, with a total word count of 214295 words, were analysed in order to gain insight into the students' developing self-directed learning skills, and other issues which were important to them. The blogs were written by the 113 students who submitted this part of the portfolio and gave their permission for their files to be analysed. The blogs were exported from the Blackboard virtual learning environment in order to programmatically perform a word count. Microsoft Access was used to store and search the corpus by category, and SPSS was used to perform inter-rater reliability statistics.

Thematic analysis (Hayes, 2000) was used to broadly categorise the blogs into the following areas of interest: self-directed learning; emotional expression; and social support. The emotional expression and social support categories are related to Deng and Yuen's social/psychological dimension, whereas their cognitive dimension is included in the self-directed learning category. For simplicity, the author coded each excerpt with only one category. Excerpts were generally between one and five sentences long but this varied according to the meaning of the text; an attempt was made to code sentences which expanded on the same thought together in one excerpt. There were 1935 excerpts coded. Examples of the sorts of content which emerged under each heading are given below. These examples were given to the second rater to train her on the coding scheme.

\section{Self-directed learning}

This category is used for blog excerpts where the student is thinking about his own learning. It includes setting goals, planning work, deciding on how to respond to peer reviews, selecting between creative ideas, monitoring progress and evaluating his own performance and product. Guidelines for deciding whether an excerpt should be classed in this category are shown in Table 1. These guidelines were derived by the author after an initial pass through the corpus, based on knowledge about self-directed learning from the literature.

\begin{tabular}{|l|}
\hline In this excerpt the student... \\
\hline Estimates how hard or easy a task or subtask is \\
\hline Scales back task given task difficulty estimation \\
\hline Decides to switch strategy \\
\hline Decides on challenge for himself - involves assessing own abilities \\
\hline Sets a goal of what to work on e.g. what creature to build \\
\hline Plans what to do next time \\
\hline Reflects: looks back over a long period (e.g. semester) \\
\hline Decides where to get help from \\
\hline Improves on method to make product better \\
\hline Decides there isn't enough time to do something \\
\hline Decides he need to spend more time on other modules/activities \\
\hline Decides which skills to develop \\
\hline
\end{tabular}


Considers how to advance his own learning

Decides on pros and cons of software to use

Compares his own implementations/algorithms to those used in Second Life itself

Identifies that the method he uses now might cause him problems later

Decides how to respond to peer suggestions

Identifies why something is hard

Selects between creative ideas

Table 1. Coding guide for self-directed learning category.

After the initial categorisation, each excerpt included in the self-directed learning category was subcategorised as relating to planning( Table 2), evaluating( Table 4), monitoring(Table 3) or help seeking. These sub-categories were chosen as a convenient way to group the main sorts of skills which the students demonstrated as identified during the initial categorisation phase.

In the planning sub-category, the students plan their work including what to build and how to go about it. This is usually at a lower level (day to day) than monitoring. In the help seeking subcategory, the student recognises that she needs help and possibly decides what the best source of help will be.

In this excerpt the student...

Generates own goals

Decides what to build

Compares/selects between ideas

Decides what to work on next time

Plans subtasks in detail

Manages a task

Plans which method to use

Table 2. Coding guidelines for planning sub-category.

Monitoring is usually at a higher level than planning, when the student periodically reflects on their progress so far.

In this excerpt the student...

Identifies that progress is slow

Identifies that time is running out

Decides to switch strategy for learning

Realises that he doesn't understand a concept

Realises a particular way of learning is or is not effective

Manages time or resources (e.g. how much effort to put into this module compared to others)

Table 3. Coding guidelines for monitoring sub-category.

In this excerpt the student comments on...

The difficulty of a task

Their own performance

A product they have created

Whether an activity is challenging for them

Whether and how to respond to peer review

The learning environment (e.g. the software or text book)

Whether the method they have used could be improved, or whether a method is appropriate

Table 4. Guidelines for coding evaluation sub-category. 


\section{Emotional expression}

Emotional expression refers to the academic emotion, motivation or attitude which accompanies the student's learning, as well as his reasons for wanting to complete a task. These can be either positive or negative. The guidelines used to decide whether an excerpt belongs to this category are shown in Table 5 .

\begin{tabular}{|l|}
\hline In this excerpt the student... \\
\hline Mentions something is fun or enjoyable \\
\hline Has a playful attitude to their work (e.g. mentions their pet in a humorous way) \\
\hline Is proud of their work (this can be implied in the choice of words as well as stated directly) \\
\hline Is disappointed in their work or progress \\
\hline Feels confident or has high self efficacy \\
\hline Lacks confidence or has low self efficacy \\
\hline Feels frustrated, stressed, anxious, irritated, ashamed or angry \\
\hline Doesn't want to complete a task \\
\hline Is looking forward to completing a task \\
\hline $\begin{array}{l}\text { Has an affective attitude towards a particular learning task (e.g. it was particularly useful, or } \\
\text { it was a waste of time) }\end{array}$ \\
\hline
\end{tabular}

Table 5. Guidelines for emotional expression category.

\section{Social Support}

Excerpts were coded as social support when the blog author interacted with peers using blog comments, when they mentioned working with a peer in the labs, or receiving help from others. Peer review is a special case, because if the student is commenting on the peer review and considering how they will improve their work, this counts as self-directed learning. The coding guidelines for deciding whether an excerpt belongs in this category are shown in Table 6.

\begin{tabular}{|l|}
\hline In this excerpt... \\
\hline Student offers help to others as part of their own blog post \\
\hline Student offers encouragement as a comment on another student's blog post \\
\hline Student asks a question using blog comments \\
\hline Blog author replies to question asked by commenter \\
\hline Student asks question in post \\
\hline Blog commenter answers question \\
\hline Blog author asks for opinion \\
\hline Commenter give opinion \\
\hline Student offers help/ resources in blog comment \\
\hline Student offers advice on strategy in blog comment \\
\hline Student describes learning with another student in the lab \\
\hline Student describes getting or giving help to a peer \\
\hline Student reflects on peer learning in general \\
\hline Student reflects on peer review process, or thanks peers for reviews \\
\hline
\end{tabular}


Table 6. Coding guide for social support category.

\section{Inter-rater reliability}

Ten percent of the excerpts coded were randomly chosen to be categorised by a second rater, who was first trained on a coding scheme written by the author. This resulted in a Kappa value of $0.768(p<.001)$, which is considered to be excellent agreement (Fleiss, 1981). The contingency table (see

\begin{tabular}{|l|l|l|r|r|r|}
\hline & & Rater 1 & & \\
\hline \multirow{2}{*}{ Rater 2} & Emotional expression & Self directed learning & Social support \\
\hline & Emotional expression & 26 & 11 & 75 & 1 \\
& Self directed learning & 11 & 1 & 2 & 44 \\
\hline & Social support & 1 & 1 & \\
\hline
\end{tabular}

Table 7) shows that the most common disagreement was between the emotional expression and self-directed learning categories, which is not surprising, given prior research that suggests that affect is woven throughout learning experiences.

\begin{tabular}{|l|l|l|r|r|r|}
\hline & & Rater 1 & & \\
\hline & & Emotional expression & Self directed learning & Social support \\
\hline Rater 2 & Emotional expression & 26 & 11 & 1 \\
\hline & Self directed learning & 11 & 75 & 1 & 4 \\
\hline & Social support & 1 & 1 & 44 \\
\hline
\end{tabular}

Table 7. Contingency table for inter-rater reliability for main categories.

The second-rater then sub-categorised a random ten percent of the excerpts coded by the first rater as selfdirected learning according to instructions written by the first rater. The kappa value was $.551(p<.001)$. As this is considered to be only "fair" agreement (Fleiss, 1981)the contingency table was examined (see Table 8). It was decided to collapse evaluation and monitoring into a single category as the high disagreement between these categories was reducing the reliability.

\begin{tabular}{|r|l|r|r|r|r|}
\hline & Rater 1 & & & \\
\hline \multirow{2}{*}{ Rater 2 } & Planning & Monitoring & Evaluating & Help Seeking \\
\hline & Monitoring & 21 & 2 & 2 & 0 \\
\hline & Evaluating & 5 & 5 & 0 & 0 \\
\hline & Help Seeking & 0 & 5 & 37 & 0 \\
\hline
\end{tabular}

Table 8. Contingency table for inter-rater reliability for self-directed learning sub-categories.

\section{Results}

\section{Descriptive Statistics}

One hundred and thirteen of the students who submitted their blogs as part of their portfolio gave permission for them to be analysed (only three students withheld permission). The blog corpus totalled 214295 words. The descriptive statistics for total word counts, total number of posts and mean word count are shown in Table 9. The kurtosis for total word count was positive (3.64) indicating that more values were in the tails of the distribution rather than clustered around the mean. There was positive skewness (1.8), indicating that there were a greater number of small total word counts than large word counts. One student wrote considerably more than his peers at 9382 words but this outlier was retained for analysis because the content was on task and provided a rich source of data. 


\begin{tabular}{|l|l|l|}
\hline & Mean & Standard deviation \\
\hline Total word count & 1953.39 & 1787.73 \\
\hline Total number of posts & 10.96 & 7.42 \\
\hline Mean word count per post & 171.85 & 129.56 \\
\hline
\end{tabular}

Table 9. Descriptive statistics for blog word counts.

The word counts indicate that the students put a reasonable amount of effort into the blogs, producing on average the equivalent of a $\mathbf{2 0 0 0}$ word essay spread out across several posts. On average, they posted entries in their blog just under once a week. There was a wide variation in the effort students put in to the blogs as measured by the word count; qualitative analysis indicates that longer, more frequent posts are often associated with higher quality reflection.

\section{Relative frequencies of self-directed learning skills in blogs}

Table 10 shows the percentage of students whose blog contained excerpts which were coded with the broad categories, as well as the percentage of all excerpts which were coded using those categories. The former indicates the proportion of the class whose writing displayed a category of interest while the latter shows how prevalent the categories are across all the learning logs. Table 11 shows the same for the self-directed learning sub-categories. It can be seen that the majority of the students' writing indicated some self-directed learning was taking place (96\%) even if this was at the most basic level of evaluating their progress. This is not unexpected, given the assignment instructions and the lecture material devoted to examples of how to write a good learning log. Similarly, a high proportion of the student writing showed emotional expression (77\%). Half of the excerpts analysed were related to self-directed learning, while around a quarter related to social support and just under a fifth related to emotional expression. Only three of the students' learning logs contained no excerpts relating to any of the categories under analysis, which implies that most students understood and carried out the task correctly.

\begin{tabular}{|l|r|r|r|r|}
\hline Category & $\begin{array}{l}\text { Number } \\
\text { students }\end{array}$ & $\begin{array}{l}\text { Count of } \\
\text { excerpts }\end{array}$ & $\begin{array}{l}\text { \% of } \\
\text { students }\end{array}$ & $\begin{array}{l}\text { \% of all } \\
\text { excerpts }\end{array}$ \\
\hline $\begin{array}{l}\text { Emotional } \\
\text { expression }\end{array}$ & 87 & 351 & 77 & 18 \\
\hline $\begin{array}{l}\text { Self-directed } \\
\text { learning }\end{array}$ & 108 & 972 & 96 & 50 \\
\hline $\begin{array}{l}\text { Social } \\
\text { support }\end{array}$ & 94 & 473 & 83 & 24 \\
\hline
\end{tabular}

Table 10. Frequency of categories

\begin{tabular}{|c|c|c|c|c|}
\hline & $\begin{array}{l}\text { Number } \\
\text { students }\end{array}$ & $\begin{array}{l}\text { Count of } \\
\text { excerpts }\end{array}$ & $\begin{array}{l}\% \text { of } \\
\text { students }\end{array}$ & $\begin{array}{l}\% \text { of all } \\
\text { excerpts }\end{array}$ \\
\hline Planning & 83 & 280 & 73 & 14 \\
\hline $\begin{array}{l}\text { Evaluating } \\
\text { and } \\
\text { monitoring }\end{array}$ & 103 & 642 & 91 & 33 \\
\hline $\begin{array}{l}\text { Help } \\
\text { seeking }\end{array}$ & 15 & 24 & 13 & 1 \\
\hline
\end{tabular}




\section{Table 11. Frequency of sub-categories.}

Around half of the excerpts related to self-directed learning, and $33 \%$ were related to the sub-skill of evaluating and monitoring learning. $25 \%$ of the excerpts were related to social support, reflecting the module's emphasis on collaborative activities such as peer review, pair programming, and commenting on group blogs. A possible explanation for the low proportion of help seeking excerpts (1\%) is that they tended to seek support from other people rather than from resources such as textbooks and so these excerpts were categorised instead under the social support category,.

\section{Self-directed Learning}

Evidence from the learning logs indicates that most of the students were capable of reflective writing which gave an account of their self-directed learning strategies. The qualitative analysis indicates that the students set their own goals, critically evaluated the learning environment, identified gaps in their learning (Loyens, Magda, \& Rikers, 2008) and engaged in the self regulatory behaviours of planning (Brown, 1987), evaluating success(Boekaerts, 2003), predicting outcomes and scheduling strategies (Brown, 1987). There is also some evidence relating to the students' meta-cognitive knowledge, meta-cognitive experience (Flavell, 1979), and some indication of the students' self efficacy, persistence and willingness to put in effort(Vrugt \& Oort, 2008). The level of self-directed learning ability demonstrated in the writing varied widely, however. Sub-skills relating to evaluation were most commonly used by students, whereas planning sub-skills were less frequently employed. Students were more inclined to evaluate their task performance directly after lab sessions and less likely to evaluate their progress on the project as a whole. There was also a general tendency for students to blog regularly early in semester (up to around week 5), blog less frequently for some weeks, then blog again in response to peer reviews at week 10 , followed by a final reflective blog at the deadline in week 12 . There are several possible reasons for this. One is the general mid-semester "dip" in student attendance and motivation which is commonly noted by staff in the department. It could be partly related to assignment deadlines for other continuously assessed modules which require the students to direct their attention away from the Interactive Systems module. It could also be that as the lab exercises grew more difficult throughout semester, the students were less likely to reach the final question on the lab sheet which was a prompt to blog about their learning during the session. That is, they were spending cognitive effort on working on a task itself rather than meta-cognitive effort on reflecting on their success at the task. In spite of these possible pressures not to blog during the middle of semester, the more effective self-directed learners did use their blogs as a way of monitoring their progress on the interactive pet project. This enabled them to plan how to use their time effectively for this module and take steps to put their project back on track if it was not progressing as intended. In contrast, those learners who did not plan were more inclined to panic towards the end of the semester when the deadline grew nearer and they realized that they had run out of time to complete the pet that they originally intended to make. This suggests that the students could benefit from more structured prompting from staff to plan and monitor their progress around the middle of the project, and some help in managing their time given the deadlines on other modules.

\section{Social support}

One of the students summarised why he found learning logs useful in a reflective post at the end of the module: "I liked the idea of learning logs for a few reasons, you could find out the name of the pet author if you spotted a pet you liked and wanted to talk to them about it. Alternatively, you could look through people's logs to see how they did things, what their pets looked like, how well they were progressing, find solution to problems you may have had, or just suggest ideas of your own in your own blog for others to see." This emphasises the educational value of the social dimension to blogging. 
Not all the study groups established a regular pattern of commenting on each others' work, but the groups which did interacted in a very supportive way. The students co-regulated by helping their peers to achieve their individual goals (blog exercises relating to shared enterprises might encourage shared regulation). The most common type of comment was simple praise of the blogger's work or a friendly reassurance and encouragement to persist if the blogger was finding something difficult. Occasionally the commenter would give domain specific help such as a pointer to learning materials or a hint about a method of solving a problem. Only one group in which the students knew each other had negative comments, but from the context, these appeared to be jokes among friends rather than serious criticisms (e.g. "I am firmly of the opinion that you have WAY too much spare time on your hands"). It is worth noting that there is potential for students to become demoralised by reading the posts of more experienced students in their group. For example, a particularly gifted student wrote about the lab exercises "I think you only need about 6 different lines of code for all 6 exercises. If anyone is working on the lab sheet alone for this lab it shouldn't take you more than 5-10 minutes if that- that's if you're coming to the lectures of course ;)". In fact, even for students who diligently attend the lectures the exercises will take considerably longer unless they happen to be as experienced at programming as the blogger. One blog comment indicates that a student recognises that one of his study group is much further ahead than him: "My god I'm in a group with genius". Some students with low confidence and self efficacy wrote about how they were demoralised by the accomplishments of their peers, whether they encountered them when mentioned by the lecturer, or noticed it on other students' screens in the labs, or in the virtual world. Of course, it is potentially educationally useful for students to observe and emulate others work assuming that they can regulate motivational reactions to this. It might therefore be useful for the teacher to look out for posts which might inadvertently make peers feel bad and put them in context for the rest of the study group.

The commenters offered cognitive support to their peers on occasion, but there was only one comment which indicated that a student was trying to help a peer with self-directed learning: "The blog needs to more lengthy and detailed. The reflection is very short, and needs to show what action will be taken next." However, this represents an opportunity to expand the role which study group members play in supporting their peers, as discussed later.

\section{Emotional expression}

The high proportion of students blogging to express emotion (77\%) is consistent with Deng and Yuen's argument that emotional expression is a key aspect of educational blogging. The blurring of the self-directed learning and emotional expression categories which became apparent through measures of inter-rater reliability support Deng and Yuen's claim that "it is the combination of the expressiveness and reflection that makes academic blogging a powerful educational tool”(Deng \& Yuen 2011;449). (Zimmerman \& Tsikalas, 2005)also emphasise how self-reflection involves "affective and motivational reactions to one's self regulatory efforts" (267).

The blogs suggest that most of the students actively engaged with making their pets and found the task intrinsically motivating. The blogs were also a good source of data on student attitudes and affect, which often coloured meta-cognitive activities such as performance evaluation, as predicted by the work of (Boekaerts, 2003)There would often be a pattern of students feeling demoralised if they had failed to complete a lab task or if their pet was not up to the standard which they had originally envisaged. They would often become frustrated or disappointed if they failed to achieve a creative goal which they had set for themselves; this is almost inevitable on a creative project where the student has insufficient experience to estimate task difficulty accurately. Learning emotional regulation is part of creative work but learners may initially require reassurance and encouragement from peers or teachers to prevent it denting their confidence. On a more positive note, completing a lab task successfully or putting their pet designs into 
practice often evoked positive activating emotions of pride and enjoyment. The blogs gave insight into a motivational problem which occasionally occurred in students with low self-efficacy where they would underestimate their own performance and become anxious when comparing their work to their peers. Confidence problems are common in novice programmers and blogs could be used to help teachers identify such students in order to give them additional support. The emotional expression data from this corpus merits further study from the perspective of promoting student engagement, an issue which is particularly important for first year students. We need to know more about which features of an open ended creative project lead to positive and negative emotional experiences, and the most effective ways of assisting students in managing these contradictory feelings.

\section{Case Studies}

As self-directed learning skills develop over time, it is instructive to consider the trajectory of student learning in this area of the course of the semester. Four case studies have been selected to illustrate how indications of self directed learning in blog posts and comments relate to future learning as evidenced by further blog entries or the final product. The case studies were chosen to highlight a range of behaviour: Students $A$ and $B$ are competent and less competent self-directed learners respectively, and take contrasting approaches to working with peers. Students $C$ and $D$ contrast in regulation of motivation and affect as well as their interactions with peers.

\section{Student A: successful self directed learning}

Student A, although new to university, was very experienced in carrying out substantial technical projects in his own time at home. From the beginning of the project he set himself clear goals towards completing his pet which was to be a dancing dinosaur. He put a good deal of effort into planning by considering the strengths and weaknesses of potential problem solving strategies e.g. "In my mind the disadvantages outweigh the advantages, as limited time may be given to modelling so that the scripting can be started. I will use an external program to model some of the more detailed parts of the dinosaur, but only as a last resort." In some cases he set himself dates to complete self-set sub-goals, but in another case he explicitly chose not to, writing "My experience with modelling has taught me that it can be a lot harder than it looks- so I'm not setting any kind of estimated date when I think this import script will be completed and working." Student A also generated sub-goals which were not directly related to the completion of his pet; he decided to set himself the tasks of writing a tutorial document for other students to help them with an aspect of 3D modelling which he had researched; and also created a Second Life object which his fellow students could use to summon assistance from peer tutors or staff. The tasks which he set himself involved a considerable amount of independent research online and were technically challenging.

Student A regularly evaluated both his product and his progress. While modelling his dinosaur, he was critical yet realistic and pragmatic, writing posts such as "I've managed to get a first draft done on the main body of the dinosaur- it's far from perfect but definitely good enough to be workable." and "For the sake of time and getting started I have left the toes in this fashion, however when it comes to the time that I have a fully completed first draft of the dinosaur, before I start scripting the model I will optimise the toes to have a higher degree of realism".

This student was persistent and hardworking in carrying out his plans. However, around half way through the module he encountered a technical problem out with his control which made it impossible to complete his pet as intended. Second Life has a limit to the number of sub-parts an object can consist of and so it was not possible to import the dinosaur on which he had expended considerable effort into Second Life. This disappointment led to a spiral of negative affect but interestingly, not a reduction in effort in the long term. At this stage he wrote: "Struggling to find time to work on the pet. There's a lot of other projects whizzing 
around at the moment at so this is going pretty slowly... just need to get it to a stage where it'll get an OK grade- I'm not sure I'll be able to get much more than that considering the time I have right now." This represents a lowering of his expectations, and further in the same post is the first realisation that his original aim might not be possible. "I might have to scrap the pet entirely if I take up another programming quest that was offered to me earlier today- might go and have a word with [the lecturer] to see what she thinks of it all.... *sigh*. The dino would have been good... :)" The other programming "quest" which he refers to was suggested by the lecturer when it became apparent that his technical problems relating the dinosaur would not be soluble. The new problem - to create a simulated flock of birds- was also challenging but possible within the constraints of Second Life. After accepting this challenge, the student's posts increasingly indicate the negative activating emotion of anger rather than the positive activating emotions of enjoyment or pride which characterised his earlier posts. For example "Getting very tired of SL now- the language restraints and the things that make you go "Ah!" Looking forward to finishing this module now if I'm entirely honest- and getting on with some other work." and "I was not in the best of moods to begin with. Usually I have the will power to force myself through yet another tedious session of Second Life, attempting to script an object which refuses point black to save itself at all." Although his motivation was low, he was able to regulate his emotion and motivation sufficiently to successfully complete his flock of birds to a very high standard.

Student A was deeply involved in providing help to his fellow learners and appeared to enjoy this. He volunteered to provide face to face technical help to the students in lab classes as well as providing help through the blogs. His helpfulness is apparent from the posts of other students who referred to his assistance and from the comments which he left to other students both in his study group and beyond. His comments were emotionally supportive and sometimes gave ideas for improving their pets e.g. "Nice idea about having a particle system for the smoke. If you communicated between the objects you could make the cigar size decrease as he gets through smoking it. Then when cigar size is less than whatever he could throw it away, and light up another one (he could rez an object within his inventory)." Student A did not appear to seek help from the other students but this is likely because his technical abilities were such that very few students were in a position to provide it.

In summary, the blog posts and the pet which he completed indicate that Student A is a self-controlled selfdirected learner capable of planning, monitoring and evaluating his own work in a sophisticated fashion. He was also able to regulate his motivation to help him submit high quality work in spite of negative affect induced by unfortunate features of the learning environment. Blogging gave him a vehicle for planning and evaluating his project, venting his negative emotions and helping his peers.

\section{Student B - struggling to self-direct}

Unlike Student A, Student B did not use his blog to plan what his pet should be, or how his work should progress. He started his blog late, and did not decide on a pet idea until late in semester. When he selected his pet, it was a pragmatic decision based on what would be low effort, rather than because of a creative ambition: "Picked a pet and started to build him. I picked a cow as a pet though I am still uncertain of whether it will be worth sticking to due to its lack of animation and interactive ability with my scripting, besides eat and reproducing. A quiz and chatbox Cow just doesn't seem right, but I will see what my building and scripting ability is able to produce within this coming week. I have some scripts saved that were developed in the labs though I seem to have lost a few somehow or are hidden away within some random objects in my inventory. With these basic scripts available to me I hope to build on them and develop them during the week to make my pet." In the same post the student wrote: "Due to the now apparent time constraints I have not so wisely inflicted upon myself I'm not in much of a position to be fussy on what I produce for the final result. I am curious as anyone to see how it all turns out." This detached attitude is rather different from most of the 
other students who tended to have an emotional investment in their pet ideas and who became anxious if they thought their progress was slow.

Student B did not often evaluate his work in his blog and did not regularly monitor his progress. His early reflections on a lab session suggest that he found it difficult to pinpoint what caused his technical problems: "The glowing sword was more difficult and have yet to get it working correctly, I don't know if I tried to make it too complicated or I just messed up somewhere.." Identifying where and why problems occur is a key skill in computer programming.

In terms of emotional expression, Student B's blog indicates that he was frustrated by difficulties he encountered. He is clearly aware that he has short comings in planning and motivation as indicated by this excerpt: "Well after doing more procrastination that was good for me I finally got down to some hard work tonight." He also acknowledged in the blog that his efforts were sometimes misdirected: "And last night was a complete waste of time I feel all I did was mutilate what little I had into a mess that didn't work in the slightest - so I scrapped it today." He wrote about an occasion where he lacked persistence "I looked into my modelling of my cow a little today and I can confidently say I don't like modeling in a 3D environment. It's niggly and positioning things and angling the prims is enough to drive a sane person crazy, so I gave up after a while which probably wasn't the wisest but I felt it was best for the safety of the lab computers and my bank balance that I did, cant afford to replace a computer that ended up out the window" but also documents more successful occasions where he wrote a working program e.g."After suffering for a fair while trying to get the structure of the code laid out right I finally got it together slowly with a breakthrough happening every now and then. It was frustrating to say the least but the success makes it almost worth it..almost."

Student B did not interact with the other students in his learning group via the blog beyond the request "if you guys have any thoughts let me know". He did not post any comments to his fellow students' blogs. His habit of working at night may have isolated him from the other students as he was not working in the labs at the same time as them.

At the end of the module, Student B reflected very briefly on his learning throughout semester "I did enjoy getting my scripts to eventually work which gave me some satisfaction after struggling along at first. The actual 3D modeling was also difficult at the beginning but the more I messed with it and practiced it became easier to work in." The pet was awarded $60 \%$ as he mastered many of the key technical concepts required of him.

In summary, Student B's blog gives the impression that he needs to develop further self-directed learning skills in order to successfully plan and complete a project without frustration and difficulty. His learning could also be improved by more frequent and accurate self-evaluation. His writing indicates lack of engagement with the task and the lack of comments suggest that he could have benefited from interacting with his fellow students more. On the other hand, the fact that he wrote blog entries at all gave the staff some insight into these problems so they could provide him with appropriate help in the future. Students who write nothing at all in their blogs are harder to assist.

\section{Student C: struggling with negative affect}

Student C's blog shows that he was conscientious and committed to his pet project. It demonstrates that he has the ability to plan and evaluate his product as well as monitor his progress. However, these self directed learning skills are accompanied by negative affect and low self-efficacy. His initial posts indicate that he is unhappy with his perceived abilities but has a fixed mindset which prevents him from trying to improve them e.g. "I'm very worried about this project, as I have little to no imagination." and "I wish I wasn't so lazy". When planning his pet cat, his reasonable plans are qualified by negative affect e.g. "The shapes are too 
simple as well, but I have no idea what other shapes I could really use. Gah! I have no idea what to do now". Although Student C correctly identified that he was managing to complete early lab exercises he was unjustifiably pessimistic about how he would cope with more difficult exercises in the future "There has been nothing too complex yet. I think I'll struggle with the scripting though."

The student struggled with negative activating emotions of shame and anxiety throughout his blog entries, even although his technical progress was in reality rather good. He compared his performance negatively to others as demonstrated in the following excerpt "I'm really worried. I feel like I'm miles behind the rest of the class. If you just have a look around the island [Second Life environment], there are so many objects that can do things. I have failed already."

At the end of the module Student C evaluated his learning in a slightly more optimistic light "I did more than I expected I would be able to do considering that I've had no real coding experience before coming to university. I had lots of trouble at the start, but it all just clicked with me at some point. I started finding it a bit easier. That's kind of the way I work." He was awarded $70 \%$ for his pet, indicating that although he had difficulty managing his anxiety, he was competent in metacognition and cognition.

In terms of social support, Student $\mathrm{C}$ was willing to offer helpful comments to his learning group but chose not to respond to a friendly comment from a peer on one of his early posts. His comments offered emotional support to his peers but were characteristically self deprecating e.g. "I know what you mean about the perspective. It's so hard to align things in Second Life. It'd be much easier if you didn't have to create object in the world. I'd rather have it just open some sort of editor that's pretty much the same as what we have now, but you were able to freely move the camera around.Sorry if that didn't make any sense. : $\mathrm{S}^{\prime \prime}$

In summary, Student C's learning experience appeared to be emotionally difficult although he did use some successful self-directed learning strategies. He used the blog as a tool to plan his project, monitor his progress and support other students in his group. The negative affective content of the blog enabled his instructors to see his anxieties so that they can be addressed in the future.

\section{Student $D$-successfully managing affect}

Student $D$ did not have any background in computer science, although she had previously studied management and so had some experience in directing her learning. Throughout the module she used the blog effectively to plan and evaluate her work and monitor learning. For example, she often identified gaps in her understanding as in: "I need to learn more about an object being in a Physical state though, since this requires turning the object Physical and I'm not sure I totally understand the physics of Second Life." or "Also, I learned a little more about loops (though I still don't totally understand them) and setting functions (which is very useful)." Unusually in comparison to the other students' blogs, she also evaluated the quality of the method she used to reach a solution ("there is likely a easier and more efficient way to do this (seeing as my method was very tedious to do and has tons of scripting which could probably be condensed)") and also considered switching strategies when her existing strategy did not work: "So, I'm trying to modify and adapt it to do what I want, but no luck. However, I can use a simpler version/adaptation of this to have my object move". These excerpts demonstrate that she was a competent self directed learner.

Student $D$ often started a blog post with a statement of her current emotional state with respect to her learning. Initially she wrote about her low confidence and anxiety about the new material e.g. "I'm going to be honest, yesterday's class really scared me/freaked me out. I'm still having trouble figuring out basic Second Life, so I don't feel ready to venture into the land of scripting yet." However, she worked hard in lab classes and was able to complete the assigned tasks which gave the beginnings of confidence: "But, I'm super happy that I managed to do some scripting. Well, I think I'm done for the day before I screw something up and make 
myself terrified of scripting again." In the next entry she seemed to be getting surer of her abilities: "I was concerned that Wednesday's class would throw me off-kilter again, but I think that I understood it (at least of the most part) and am even optimistic that the script I wrote will work." The posts following this tended to be optimistic, acknowledging challenges or frustrations but expressing the intention to keep trying to find solutions. She engaged in efficacy management through encouraging self talk such as "Oh well, I'm on my way. Maybe we'll learn some good new techniques in the lecture tomorrow." Student D did manage to solve the problems she encountered and was very proud of the pet tiger which she created (receiving an A grade). She evaluated her learning at the end of the module by expressing a series of positive activating emotions: "This module has been a huge learning curve, but I've enjoyed it greatly. I entered the class having never scripted or even interacted in a virtual world, and I'm leaving feeling confident in my ability to create and script within SecondLife. I really feel that my pet is a success. Of course I still have tons of ideas which I hope to still implement, but I feel good about the pet I've submitted".

Student $\mathrm{D}$ was an active participant in her study group, regularly both giving and receiving emotional support as well as technical tips. For example, one of her peers tried to comfort her on her early blog post where she lacked confidence by commenting "It sounds like that you a progressing fine, I don't think you need to be so scared of scripting. I find IIGetOwner() very useful if you are testing and don't want your object respond to everyone." In turn, she offered technical tips in her blog posts ("Also, if like me you have encountered quaternions before and are curious to know more about how mathematical quaternions relate to the rotation in SecondLife, check out the following link:") as well as specific help via comments on peers' blogs. She was always careful to respond to comments to her own blog by thanking the student or otherwise showing that she had taken their feedback or suggestions into account.

In summary, Student $D$ is a competent self directed learner who successfully regulated her initially anxious emotional reaction to a new learning situation. She appropriately adjusted her self efficacy in response to her increase in skill and this resulted in the positive activating academic emotions of enjoyment, pride and hope. Her blog entries demonstrate this emotional trajectory clearly along with the use of other self-directed learning skills. Her response to the comments and posts of other students in her study group suggest that the blog affordances for social support were particularly useful to her. 


\section{Framework for educational affordances of blogs}

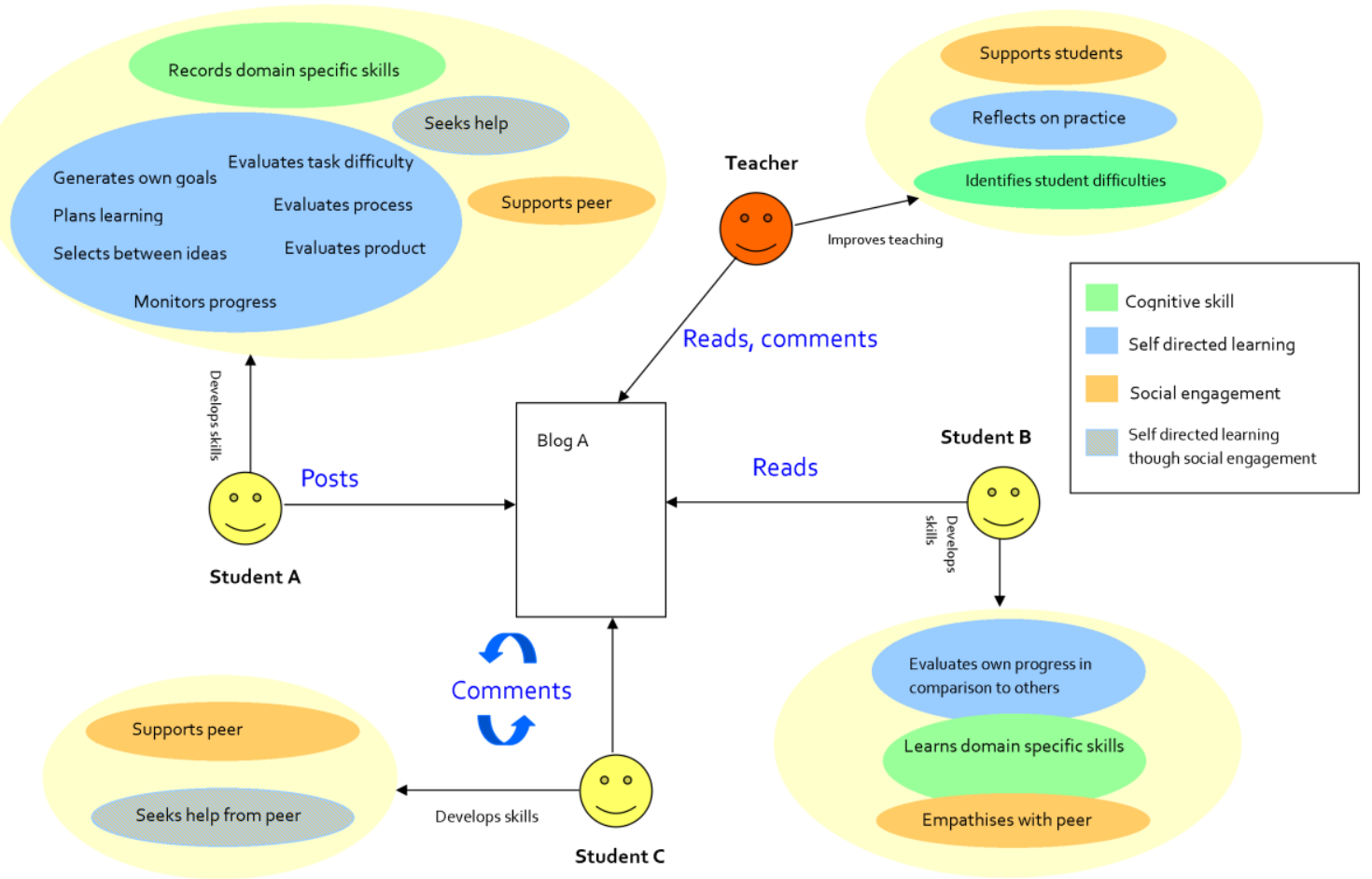

Figure 3. Framework of the educational affordances of blogs. 


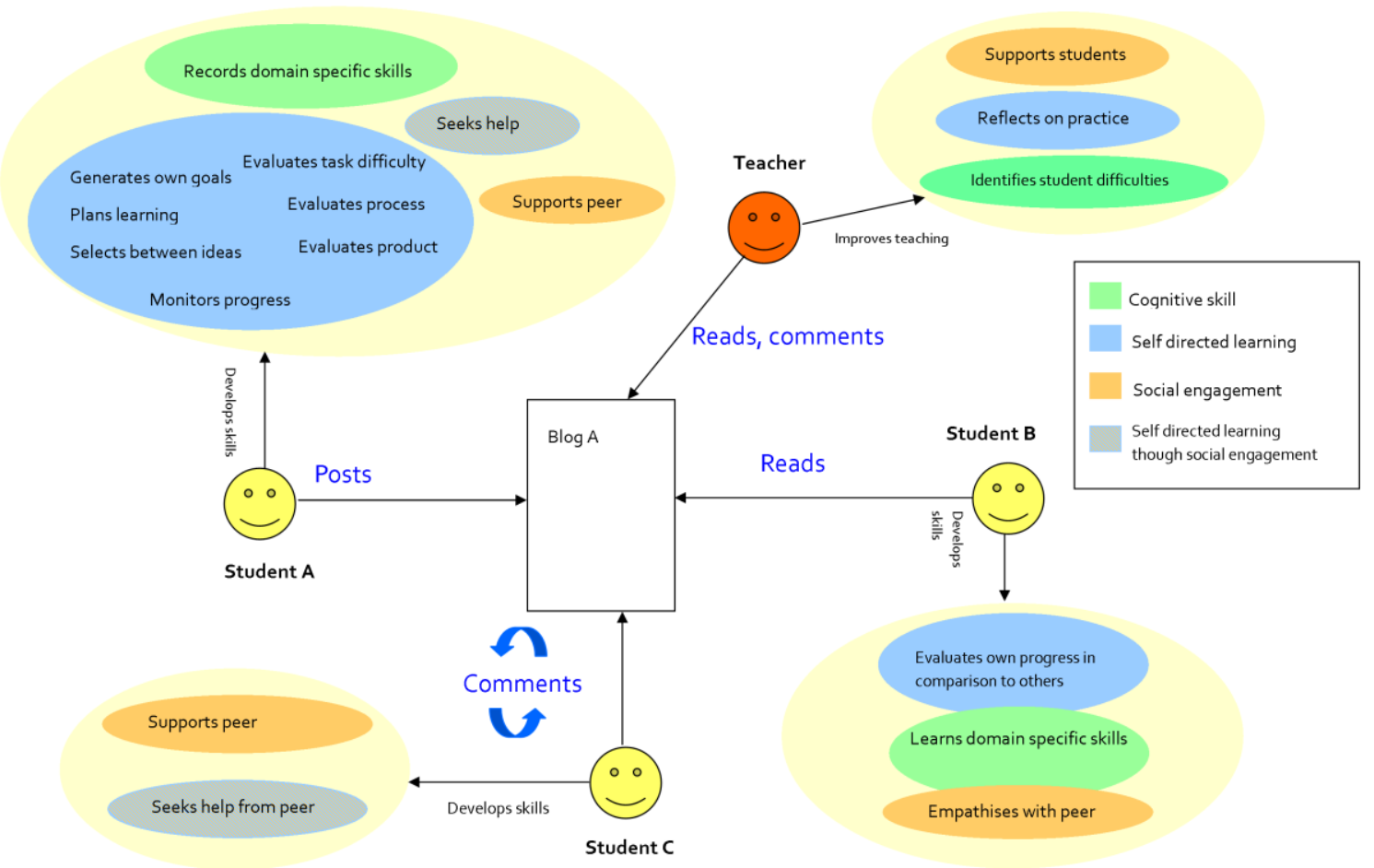

Figure 3 maps out a framework through which a community of learners and teachers can develop cognitive, social and self-directed learning skills through blogging. The learning community can consist of one or more 
teachers whose role is to read and comment on student blogs; and one or more study groups of learners whose role is to post articles to their own blogs and read and comment on the blogs of their fellow study group members. For the sake of clarity, in the diagram only one teacher and study group interacting with a single student blog is shown although all the students within the learning community have the opportunity to post, read and comment on each others' blogs and the teacher will read on comment on each learner's blog. Student A develops various skills from posting to his blog. He may also extend social support to his peers by offering tips and suggestions in his post. He can use it to record new cognitive skills which he has learned recently, such as how to use a new programming construct in the domain of computer science. While writing about his creative project, he also develops a set of self-directed learning skills. At the early stages of a project, he may be deciding what his learning goals are, or thinking of creative ideas and choosing between them. This involves evaluating the difficulty of the subtasks involved in implementing each idea. If he has finished a learning session, he might plan what he will do in the next session, or plan further ahead for the rest of the semester. Later in the project, Student A might monitor his progress with respect to his plan, and evaluate how well his learning strategy is working. Towards the end of the project he will evaluate his product. Student B reads Student A's blog and in doing so learns about some domain specific skills which Student $A$ has recorded. He can also exercise the self-directed learning sub-skill of evaluating his own progress in comparison to the progress of his peer. He may also experience empathy for student $A$ 's experience particularly if he has had a similar experience in his own studies. Student $\mathbf{C}$, who has previously read Student A's blog, has chosen to comment on it. This may turn into a conversation between students $A$ and $C$, along with other members of the learning community and potentially facilitated by the teacher. In addition to the skills Student $\mathrm{C}$ will have developed by reading the blog, the process of commenting will have given her the opportunity to support her peer with a constructive and encouraging contribution. Furthermore, she may choose to seek help from Student A with her own work if she realises that he might have the skills which she needs. The Teacher reads and comments on the learner's blogs in order to give them support and encouragement. By reading the students' records of their domain skills, she can identify misconceptions and difficulties which the class are encountering and address them in future classes. The blogs are windows onto their authors' learning, and by reading them the teacher can reflect on her own practice in order to improve the students' learning.

Table 12 illustrates each of the skills developed by the students with two examples drawn from the corpus. It is not possible to find direct evidence of the learning which takes place from reading a blog so examples from post or comments which imply learning from reading have been chosen instead. The distinction between empathising with a student and providing support is small; in the examples chosen here students who empathise with a peer acknowledge a difficulty encountered by peers but do not offer any solutions. It was in fact more common for students to follow this up with some more constructive support either emotionally by trying to comfort the student, or technically by offering programming help.

\begin{tabular}{|l|l|l|l|}
\hline Type of learning & Blog affordance & Skill & Example evidence from corpus \\
\hline Cognitive & Posting & $\begin{array}{l}\text { Records domain } \\
\text { specific knowledge }\end{array}$ & $\begin{array}{l}\text { "Today in second life I learned all about } \\
\text { prims, how to make them, move them } \\
\text { around and change their shapes and } \\
\text { sizes" } \\
\text { "loops definitely do not work if you } \\
\text { do for(int i=0;i<10;i++). No matter how } \\
\text { many times I have tried, it does not work. } \\
\text { instead, one has to initialise the variable i } \\
\text { outside of the loop." }\end{array}$ \\
\hline Social & Posting & $\begin{array}{l}\text { "This task is actually straight forward. I } \\
\text { have provided some info on methods that } \\
\text { may help you if you're still working on this }\end{array}$ \\
\hline
\end{tabular}




\begin{tabular}{|c|c|c|c|}
\hline & & & $\begin{array}{l}\text { task." } \\
\text { "Anyway here's a little list of thing I've } \\
\text { learned and you may find useful." }\end{array}$ \\
\hline $\begin{array}{l}\text { Social/ self-directed } \\
\text { learning }\end{array}$ & Posting & Help seeking & $\begin{array}{l}\text { "If anyone can see anything wrong with } \\
\text { this dinosaur and you're sitting there } \\
\text { saying "But look at [x], that's not right } \\
\text { surely!", or wishes to see it inside SL to } \\
\text { find flaws ( ;) ) then e-mail or comment } \\
\text { and I'll look into it at the same time as } \\
\text { doing the import- all comments } \\
\text { appreciated." } \\
\text { "So here's the catch; if any of you } \\
\text { managed to get your sword working and } \\
\text { are feeling charitable, I would really } \\
\text { appreciate any help you can give me" }\end{array}$ \\
\hline $\begin{array}{l}\text { Self-directed } \\
\text { learning }\end{array}$ & Posting & Generates own goals & $\begin{array}{l}\text { "[The lab exercise] was rather simple to } \\
\text { do (based loosely on last week's lab), so I } \\
\text { expanded it and made it more } \\
\text { interesting". } \\
\text { "[my program] uses states [a } \\
\text { programming concept]. I did this as a test } \\
\text { to try and familiarize myself with them." }\end{array}$ \\
\hline $\begin{array}{l}\text { Self-directed } \\
\text { learning }\end{array}$ & Posting & $\begin{array}{l}\text { Selects between } \\
\text { ideas }\end{array}$ & $\begin{array}{l}\text { "Still thinking about my pet. It'll probably } \\
\text { be a penguin. Second Life is already full of } \\
\text { dogs, cats and other common animals, but } \\
\text { I haven't seen a penguin yet, so it seems } \\
\text { to be a good idea." } \\
\text { "I also thought of a frog from the } \\
\text { bouncing motion but rejected that idea } \\
\text { for lack of passion" }\end{array}$ \\
\hline $\begin{array}{l}\text { Self-directed } \\
\text { learning }\end{array}$ & Posting & $\begin{array}{l}\text { Evaluates task } \\
\text { difficulty }\end{array}$ & $\begin{array}{l}\text { "I decided to do the school of fish over the } \\
\text { flock of birds due to the simplicity factor } \\
\text { (the flock of birds would be way too hard } \\
\text { to create in terms of design (the feathers } \\
\text { and body shape would be extremely } \\
\text { difficult) and animation (the fish would be } \\
\text { situated in a smaller confined underwater } \\
\text { area where as the birds have way more } \\
\text { room and therefore added complexity" } \\
\text { "When thinking about the behaviours of } \\
\text { the pet I was unsure on what I could make } \\
\text { it do, with the scripting seeming difficult I } \\
\text { was not sure how simple it would be } \\
\text { to even just make the pet walk a little, so } \\
\text { as for now behaviours of Garfield will be } \\
\text { very simple, until I figure out how to go } \\
\text { about making it move, hopefully though } \\
\text { by the time the project will be nearing an } \\
\text { end it will be dancing." }\end{array}$ \\
\hline $\begin{array}{l}\text { Self-directed } \\
\text { learning }\end{array}$ & Posting & Plans learning & $\begin{array}{l}\text { "Going to work my way through from } \\
\text { chapter three to six before the next lab } \\
\text { hopefully. Also, going to draw some ideas } \\
\text { down onto paper about my pet" } \\
\text { "The actual physical design of the fish will }\end{array}$ \\
\hline
\end{tabular}




\begin{tabular}{|c|c|c|c|}
\hline & & & $\begin{array}{l}\text { start at the end of this week (after the } \\
\text { final code has been tested and has been } \\
\text { logged correctly)." }\end{array}$ \\
\hline $\begin{array}{l}\text { Self-directed } \\
\text { learning }\end{array}$ & Posting & Monitors progress & $\begin{array}{l}\text { "I feel that I need to work quite a bit more } \\
\text { in my spare time, finding tutorials, } \\
\text { experimenting and so on to be able to } \\
\text { achieve the level of complexity I want my } \\
\text { pet to achieve." } \\
\text { "I am really starting to get concerned as I } \\
\text { do not see myself finishing the pet on } \\
\text { time. I've decided to ration my time } \\
\text { carefully and set targets as to what should } \\
\text { be finished when." }\end{array}$ \\
\hline $\begin{array}{l}\text { Self-directed } \\
\text { learning }\end{array}$ & Posting & Evaluates process & $\begin{array}{l}\text { "Regrets of course are that I should have } \\
\text { started earlier, worked harder etc" } \\
\text { "The things I reckon I have learned or } \\
\text { improved on most of all though aren't so } \\
\text { much technical as social as I think this } \\
\text { course really helps boost that particular } \\
\text { skill set by conferring with fellow students } \\
\text { about each others' pets and what the } \\
\text { plans for them are and also the fact that } \\
\text { the labs are quite difficult it would be } \\
\text { foolish not to socialise and get different } \\
\text { perspectives on how to do things" }\end{array}$ \\
\hline $\begin{array}{l}\text { Self-directed } \\
\text { learning }\end{array}$ & Posting & Evaluates product & $\begin{array}{l}\text { "No where near the standard of some the } \\
\text { awesome pets I have seen on the island } \\
\text { but I knew I wouldn't be able to match } \\
\text { them. Even so I'm quite chuffed at how he } \\
\text { turned out!" } \\
\text { "Despite the fact my penguin 3d model is } \\
\text { not perfect, I do like it and I think that it } \\
\text { actually looks like a penguin" }\end{array}$ \\
\hline Cognitive & Reading & $\begin{array}{l}\text { Learns domain } \\
\text { specific skills }\end{array}$ & $\begin{array}{l}\text { Blog post: "I will continue to look at the } \\
\text { blogs as always for tips and helpful advice } \\
\text { on how to solve some of the problems." } \\
\text { Blog comment: "Very good comments } \\
\text { within your code. I will try and use that in } \\
\text { my code as it makes your code much } \\
\text { easier to understand" }\end{array}$ \\
\hline Social & Reading & $\begin{array}{l}\text { Empathises with } \\
\text { peers }\end{array}$ & $\begin{array}{l}\text { Blog post: "I'll let you know how I get on } \\
\text { but it sounds like everyone was } \\
\text { struggling" } \\
\text { Blog comment:" I agree with you on the } \\
\text { idea that animating will be hard, it is quite } \\
\text { daunting," }\end{array}$ \\
\hline $\begin{array}{l}\text { Self-directed } \\
\text { learning }\end{array}$ & Reading & $\begin{array}{l}\text { Evaluates progress in } \\
\text { comparison to peers }\end{array}$ & $\begin{array}{l}\text { "I can't believe how much work has been } \\
\text { done within a week. It makes me feel } \\
\text { guilty, I'd better get started on how to } \\
\text { make objects" } \\
\text { "Well, after having a little nosy around at } \\
\text { other people's blog, they seemed to have } \\
\text { tackled the problems of SL" }\end{array}$ \\
\hline Social & Commenting & Supports peers & Blog comment: "It sounds like that you a \\
\hline
\end{tabular}




\begin{tabular}{|l|l|l|}
\hline & & $\begin{array}{l}\text { progressing fine, I don't think you need to } \\
\text { be so scared of scripting. I find } \\
\text { IGetOwner() very useful if you are testing } \\
\text { and don't want your object respond to } \\
\text { everyone." } \\
\text { Blog comment: "Hey there .. we are all } \\
\text { learning now, no-one expects us to know } \\
\text { everything. If we did then why would we } \\
\text { be here.. :) so u r not "not too clever" u r } \\
\text { just learning.. I hope that made sense.. I } \\
\text { would suggest to u as to myself - more } \\
\text { practice (takes time tho :/)" }\end{array}$ \\
\hline $\begin{array}{l}\text { Self-directed } \\
\text { learning }\end{array}$ & Commenting & Seeks help from peer \\
& & $\begin{array}{l}\text { Blog comment: "I had this same problem } \\
\text { :( what texture did you change it to in the } \\
\text { end?" } \\
\text { Blog comment: "I was wondering if you } \\
\text { knew where I could find more information } \\
\text { on responses and key word" }\end{array}$ \\
\hline
\end{tabular}

Table 12. Illustrative examples from blog corpus.

\section{Discussion}

\section{Blogging without additional face to face interactions}

The learning setting of the study described above involved learning support distributed across face to face and electronic modalities. Analysis of the social support mentioned in the students' blogs indicates that they valued face to face peer learning in the labs where they programmed in pairs or took part in peer reviews. They also found face to face help from instructors in the lectures and labs helpful. Therefore a question for further research is: to what extent can the affordances of blogs support cognitive, social and self-directed learning in the absence of additional face to face support? In their review of supporting self-regulated learning through computer based tools, (Winters, Greene, \& Costich, 2008)report mixed evidence as to whether software support can be effective in this area. They note that some studies have found a discrepancy in students' self-reports of self-regulated learning while using support software and their actual usage of the relevant tools - students typically reported using software features to support self-regulated learning skills more frequently than the software log files indicated. They found some evidence that static prompts within software can increase student planning behaviours, and note that adaptive scaffolding, such as that found in intelligent tutoring systems, can improve planning, monitoring and effective strategy use as well as increase learning outcomes. It would be possible to incorporate static prompts to assist self-directed learning in instructions to accompany the blogging task, such as the prompts used in the Interactive Systems lab worksheets. It would also be possible for teachers as blog commenters to provide support adapted to individual students. One reason for automated adaptive scaffolding in intelligent tutoring systems is to reduce the teaching load for large classes and provide more detailed feedback than the teacher's schedule permits. However, implementation of intelligent tutoring systems is notoriously time consuming and costly (Murray, 1999) and although there are some meta-cognitive tutoring systems available (see (Graesser \& McNamara, $n$ d)) these are less flexible than blogging software in the sense that a teacher can set almost any instructional task using blog software whereas adapting a tutoring system to fit a new task often requires specialist skills. Teachers with large classes who are unable to find time to provide support for all the students could use the peer coaching method suggested below. 


\section{Peer coaching of self-directed learning skills}

The commenting affordance of the blogs was useful to the students because it enabled study group members to offer emotional and sometimes cognitive support to their peers. The students appeared to appreciate the praise and encouragement from their peers and this is important in the early stages of learning to program which learners can find daunting and demoralising. When class sizes are large, support from a peer can be helpful if the teacher does not have time to comment on all the learning logs are frequently as she might wish. Furthermore, in creative projects of this sort, validation from peers is valuable in its own right, particularly if the product is inspired by popular culture in a way which might be missed by teacher staff of an older generation. The domain specific technical tips exchanged between study group members were also likely to be valuable for both the donor and recipient of the advice. The recipient could progress with their project without waiting for support from teaching staff, and the donor could benefit by applying their knowledge to solve a problem, by articulating the answer clearly and from the confidence boost of helping someone else.

However, the students did not coach each other in the development of self-directed learning skills- they were not explicitly asked to do so and it may not have occurred to them it was appropriate. White and Frederickson's work illustrates that it can be beneficial even for young students (11 year olds) to assume the role of a cognitive, meta-cognitive or social advisor for their peers (White \& Frederiksen, 2005). Working in small groups, students would take responsibility for a single role such as "planning manager", "productivity manager" or "reflection manager" to ensure that the group paid attention to the relevant aspect of the learning process. By externalising and distributing the roles and turning them into a social process, White and Frederickson supported the acquisition of self regulated learning skills for science inquiry. Gradually, the students took increasing responsibility for more of the roles by themselves. White and Frederickson found that students who took part in their pedagogical activities including a reflective journal and role-playing made significant gains in meta-cognition in comparison to a control class. Given the success of this approach in young learners, a fruitful area of future research would be to investigate the extent to which a study group of learners could take on roles as meta-cognitive advisers to their peers through blogging. White and Frederickson found that when given the option to choose which roles to assume, students chose social support roles, followed by meta-cognitive roles, followed by cognitive roles. Zimmerman and Tsikalas (2005) speculate this is because the students feel most competent at performing social roles and that as they acquire competence in meta-cognitive or cognitive roles they would become more interested in performing them. This is consistent with the findings of the current study to some extent - students provided social support through blogs most frequently, occasional cognitive support and almost never meta-cognitive support. In Zimmerman and Tsikalas's interpretation this would be because the students had competence in the necessary cognitive skills of programming through the lab exercises they had completed successfully, but were less confident in their meta-cognitive skills during the project because they did not yet know whether they would prove effective for completing the portfolio on time. From this point of view, it would be beneficial to introduce a cascaded learning scheme for blog commenting in which more experienced students with some mastery in self-directed learning in a creative project acted as coaches for novice students.

\section{Conclusion}

The development of self directed learning skills is an important goal of higher education, particularly in the first year. Qualitative analysis of a corpus of blogs written by first year computer science students indicates the ways in which the educational affordances of blogs can support the self directed learning skills of generating one's own learning goals, planning how to tackle a problem, evaluating whether learning goals have been met, and re-planning based on this evaluation. As well as providing opportunities to practice selfdirected learning, the blogs enabled students to express their emotional experiences of learning and to 
exchange social and cognitive support with their peers. The emotional support of peers was valuable to the novice learners in this study and represents a useful strategy for enhancing the experience of first year students. The affordances of educational blogs could also be used for peer coaching of meta-cognitive skills, an approach which deserves future study.

\section{References}

Alexander, P. (2008). Why This and Why Now? Introduction to the Special Issue on Metacognition, Self-Regulation, and Self-Regulated Learning. Educational Psychology Review, 20(4), 369-372. Retrieved from http://dx.doi.org/10.1007/s10648-008-9089-0.

Boekaerts, M. (2003). Towards a model that integrates motivation, affect and learning. BJEP Monograph Series II, Number 2 - Development and Motivation, 1(1), 173-189. British Psychological Society. Retrieved from citeulike-article-id:641908.

Boud, D. (2001). Using Journal Writing to Enhace Reflective Practice. NEW DIRECTIONS FOR ADULT AND CONTINUING EDUCATION, 20, 9-17. Retrieved from http://blogs.ubc.ca/cs/2/files/2009/04/journalwritingreflectivepractice1.pdf.

Boulay, B. du, Avramides, K., Luckin, R., Martinesz-Miron, E., Rebolledo Mendez, G., \& Carr, A. (2010). Towards Systems That Care : A Conceptual Framework based on Motivation , Metacognition and Affect. International Journal of Artificial Intelligence in Education, 20(3).

Brown, A. (1987). Metacognition, executive control, selfregulation and other more mysterious mechanisms. In F. E. Weinert \& R. H. Kluwe (Eds.), (p. 65-116). Hillsdale, New Jersey: Lawrence Erlbaum Associates.

Deng, L., \& Yuen, A. H. K. (2011). Towards a framework for educational affordances of blogs. Computers \& Education, 56(2), 441-451. Elsevier Ltd. doi: 10.1016/j.compedu.2010.09.005.

Dweck, Carol S. (2007). Mindset: The new psychology of success. Ballantine Books. Retrieved from http://search.ebscohost.com/login.aspx?direct=true\&db=psyh\&AN=2006-08575000\&loginpage $=$ login. asp\&site=ehost-live.

Elliott, E. S., \& Dweck, C S. (1988). Goals: an approach to motivation and achievement. Journal of Personality and Social Psychology, 54(1), 5-12. American Psychological Assn. Retrieved from http://www.ncbi.nlm.nih.gov/pubmed/3346808.

Ferdig, R. E., \& Trammell, K. D. (2004). Content delivery in the "Blogosphere." Technological Horizons in Education Journal. Retrieved from http://www.thejournal.com/magazine/vault/articleprintversion.cfm?aid=4677 .

Flavell, J. (1979). Metacognition and Cognitive Monitoring. American Psychologist, 34(10), 906-911.

Fleiss, J. L. (1981). Statistical methods for rates and proportions (2nd ed., p. xviii,321p.). New York ; Chichester: Wiley. 
Graesser, A., \& McNamara, D. (n.d.). Self-Regulated Learning in Learning Environments With Pedagogical Agents That Interact in Natural Language. Educational Psychologist, 45(4), 234-244. Retrieved from http://www.informaworld.com/10.1080/00461520.2010.515933.

Harris, A., Bonnett, V., Luckin, Rosemary, \& Yuill, N. (2009). Scaffolding effective help-seeking behaviour in mastery and performance oriented learners. Artificical Intelligence in Education (pp. 425-432).

Hayes, N. (2000). Doing psychological research : gathering and analysing data (p. xviii, 400p.). Buckingham: Open University Press.

Higgins, S. (2009). Learning to Learn. Durham: Beyond Current Horizons Project. Retrieved from http://www.beyondcurrenthorizons.org.uk/wpcontent/uploads/ch3_final_stevenhiggins_final.pdf.

Järvenoja, H., \& Järvelä, S. (2009). Emotion control in collaborative learning situations: do students regulate emotions evoked by social challenges? The British journal of educational psychology, 79(Pt 3), 463-81. doi: 10.1348/000709909X402811.

Kaplan, A. (2008). Clarifying Metacognition, Self-Regulation, and Self-Regulated Learning: What's the Purpose? Educational Psychology Review, 20(4), 477-484. doi: 10.1007/s10648-008-9087-2.

Kerawalla, L., Minocha, S, Kirkup, G., \& Conole, G. (2009). An empirically grounded framework to guide blogging in higher education, 31-42. doi: 10.1111/j.1365-2729.2008.00286.x.

Loyens, S., Magda, J., \& Rikers, R. (2008). Self-Directed Learning in Problem-Based Learning and its Relationships with Self-Regulated Learning. Educational Psychology Review, 20(4), 411-427. Retrieved from citeulike-article-id:3638458.

Luehmann, A. (2008). Using Blogging in Support of Teacher Professional Identity Development: A Case Study. Journal of the Learning Sciences, 17(3), p287-337.

Mayes, T. (2009). Overview of the enhancement theme 2006-08: The aims, themes and challenges. Mansfield: The Quality Assurance Agency for Higher Education. Retrieved from http://www.enhancementthemes.ac.uk/documents/firstyear/FirstYearOverview.pdf.

Minocha, Shailey. (2009a). Role of social software tools in education: a literature review. Education + Training, 51(5/6), 353-369.

Minocha, Shailey. (2009b). An empirically-grounded study on the effective use of social software in education. Education + Training, 51(5/6), 381-394.

Murray, T. (1999). Authoring intelligent tutoring systems: An analysis of the state of the art. International Journal of Artificial Intelligence in Education, 10(1), 98-129. Citeseer. Retrieved December 8, 2010, from http://citeseerx.ist.psu.edu/viewdoc/download?doi=10.1.1.97.153\&amp;rep=rep1\&amp;type= pdf.

Noushad, P. P., ERIC. (2008). Cognitions about Cognitions: The Theory of Metacognition. Retrieved from http://www.eric.ed.gov/ERICWebPortal/custom/portlets/recordDetails/detailmini.jsp?_nfpb=tr 
ue\&_\&ERICExtSearch_SearchValue_0=ED502151\&ERICExtSearch_SearchType_0=no\&accno=ED 502151.

Pekrun, R., Goetz, T., Titz, W., \& Perry, R. (2002). Academic Emotions in Students? SelfRegulated Learning and Achievement: A Program of Qualitative and Quantitative Research. Educational Psychologist, 37(2), 91-105. doi: 10.1207/S15326985EP3702_4.

Puntambekar, S., \& Kolodner, J. L. (2005). Toward implementing distributed scaffolding: Helping students learn science from design. Journal of Research in Science Teaching, 42(2), 185-217. Wiley Subscription Services, Inc., A Wiley Company. Retrieved from http://dx.doi.org/10.1002/tea.20048 DO - 10.1002/tea.20048.

Sanna Järvelä, T.-R. H. H. J. (2007). Self-regulation and Motivation in Computer Supported Collaborative Learning Environments. Learning in social practic- es. ICT and new artifacts transformation of social and cultural practices. (pp. 1-35).

Vrugt, A., \& Oort, F. (2008). Metacognition, achievement goals, study strategies and academic achievement: pathways to achievement. Metacognition and Learning, 3(2), 123-146. Retrieved from citeulike-article-id:3624474.

White, B., \& Frederiksen, J. (2005). A Theoretical Framework and Approach for Fostering Metacognitive Development. Educational Psychologist, 40(4), 211-223. doi: 10.1207/s15326985ep4004_3.

Williams, J., \& Jacobs, J. (2004). Exploring the use of blogs as learning spaces in the higher education sector. Australasian Journal of Educational Technology, 20(2), 232-247.

Winters, F. I., Greene, J. a, \& Costich, C. M. (2008). Self-Regulation of Learning within Computerbased Learning Environments: A Critical Analysis. Educational Psychology Review, 20(4), 429444. doi: 10.1007/s10648-008-9080-9.

Wolters, C. (2003). Regulation of Motivation: Evaluating an Underemphasized Aspect of SelfRegulated Learning. Educational Psychologist, 38(4), 189-205.

Zimmerman, B. J., \& Tsikalas, K. E. (2005). Can Computer-Based Learning Environments ( CBLEs ) Be Used as Self-Regulatory Tools to Enhance Learning ? Educational Psychologist, 40(4), 267-271. 